\title{
Microbial biotechnological approaches: renewable bioprocessing for the future energy systems
}

\author{
Praveen C. Ramamurthy ${ }^{1 \dagger}$, Simranjeet Singh ${ }^{1 \dagger}$, Dhriti Kapoor ${ }^{2}$, Parul Parihar ${ }^{2}$, Jastin Samue ${ }^{5,6}$, Ram Prasad $^{3 *}$, \\ Alok Kumar ${ }^{4^{*}}$ and Joginder Singh ${ }^{5^{*}}$
}

\begin{abstract}
The accelerating energy demands of the increasing global population and industrialization has become a matter of great concern all over the globe. In the present scenario, the world is witnessing a considerably huge energy crisis owing to the limited availability of conventional energy resources and rapid depletion of non-renewable fossil fuels. Therefore, there is a dire need to explore the alternative renewable fuels that can fulfil the energy requirements of the growing population and overcome the intimidating environmental issues like greenhouse gas emissions, global warming, air pollution etc. The use of microorganisms such as bacteria has captured significant interest in the recent era for the conversion of the chemical energy reserved in organic compounds into electrical energy. The versatility of the microorganisms to generate renewable energy fuels from multifarious biological and biomass substrates can abate these ominous concerns to a great extent. For instance, most of the microorganisms can easily transform the carbohydrates into alcohol. Establishing the microbial fuel technology as an alternative source for the generation of renewable energy sources can be a state of art technology owing to its reliability, high efficiency, cleanliness and production of minimally toxic or inclusively non-toxic byproducts. This review paper aims to highlight the key points and techniques used for the employment of bacteria to generate, biofuels and bioenergy, and their foremost benefits.
\end{abstract}

Keywords: Biomass, Enzymes, Fermentation, Metabolic engineering, Biofuel

\section{Background}

Formation of better-quality byproducts from biomass by use of microbes is considered as a significant asset to diminish synthetic chemical progressions, which are mainly costly, toxic, and non-renewable [1]. The

\footnotetext{
*Correspondence: rpjnu2001@gmail.com; alok.igib@gmail.com; joginder.15005@lpu.co.in

tPraveen C. Ramamurthy and Simranjeet Singh contributed equally to this work

${ }^{3}$ Department of Botany, Mahatma Gandhi Central University, Motihari, Bihar, India

${ }^{4}$ School of Plant Sciences, College of Agriculture and Environmental Sciences, Haramaya University, Box-138, Dire Dawa, Ethiopia

${ }^{5}$ Department of Microbiology, Lovely Professional University, Phagwara, Punjab, India

Full list of author information is available at the end of the article
}

rapid decline in the fossil fuels level and the increasing worldwide requirement of energy has demanded the generation of substitute fuels that can displace the traditional fossil fuels to decrease the elevated accumulation of greenhouse gases in the environment. Hence, in present day time the creation of conservative, efficient and ecologically beneficial renewable energy fuels is the main requirement around the globe that signifies the ability to instantaneously substitute the traditional fuels to decrease the adverse climatic issues [2]. Escalating attention has been concentrated on biomass application as a renewable energy resource due to the reduced levels of conventional fossil fuels [3]. Employing multifaceted microbes to produce renewable energy sources from the biomass and biological residues are of greater importance, therefore, focus 
for the synthesis of different biofuels via microbes has been gradually escalating in the present-day time [4]. This is mainly due to the metabolic multiplicity of various microbes that allows the generation of biofuels from different moieties [2].

Microbial biotechnology is an important strategy for sustainable bioprocesses in which microorganisms and their enzymes are used for the conversion of carbohydrates, lignins, glycerols into various renewable resources like bioenergy production (Fig. 1). The buildup of agronomic and industrial wastes in the fields leads to harmful environmental issues. To reduce this problem, microorganisms are of great economic importance in various biotechnological progressions such as in the microorganism fermentative methods. In addition to this, microbes are multifaceted moieties which are helpful in utilization and bioconversion of biomass as they are vital sources of enzymes with biotechnological capability [3]. Microbial glycosylated apparatuses also have significant role to alter the effect of plant contact with harmful pathogens [5] and developing technologies in microbial biotechnology that are beneficial in developing an antimicrobial vaccine and drug discovery in the present-day time [6]. Therefore, this review paper aims to review the various techniques and key points for the generation of bioenergy molecules from microbial functions and their foremost benefits. Moreover, it also focuses on the various metabolic engineering strategies implied to improve the yield of biofuels.

\section{Microbial biology and energy production}

When envisioning the influence of biotechnology in the upcoming time to the energy resources, it is a positive assurance that the generation of biofuels using microorganism may help in providing the energy supply to a greater extent and that the bioprocessing of renewable energy will highly be endorsed by nations where fossil fuel origins are absent [8]. In addition to biodiesel and bioethanol as foremost aspects of biomass energy, $\mathrm{H}_{2}$ is also recognized as an efficient and feasible facet for economic and renewable energy resource in the present and future time [9]. In view of energy expenditure prices, biofuel produced from lignocellulosic biomass using Trichoderma reesei is an effective and inexpensive method which yields ethanol directly for energy production as it does not need $\mathrm{NaClO}$ or acid hydrolysis pretreatment $[10,11]$. Microorganisms grouping as consortium instead of using a single micro-organism to elevate the biofuel production may comprise of, (i) Trichoderma reesei, for synthesize enzyme to hydrolyze lignocellulosic biomass and Saccharomyces cerevisiae, (ii) Scheffersomyces stipitis, to exploit hexose and pentose sugars respectively, possibly employed to implement CBP [12]. (iii) Cellulase and xylanase synthesized by Penicillium echinulatum, immersed in combined cellulose and sorbitol media, may assist in bioethanol formation from lignocellulosic biomass [13]. (iv) Anoxybacillus flavithermus strain TWXYL3 derived xylanase, which is thermostable and alkali stable, can highly contribute to the production of inexpensive, economical and renewable energy [14]. Thermostable enzymes are used as biocatalysts in

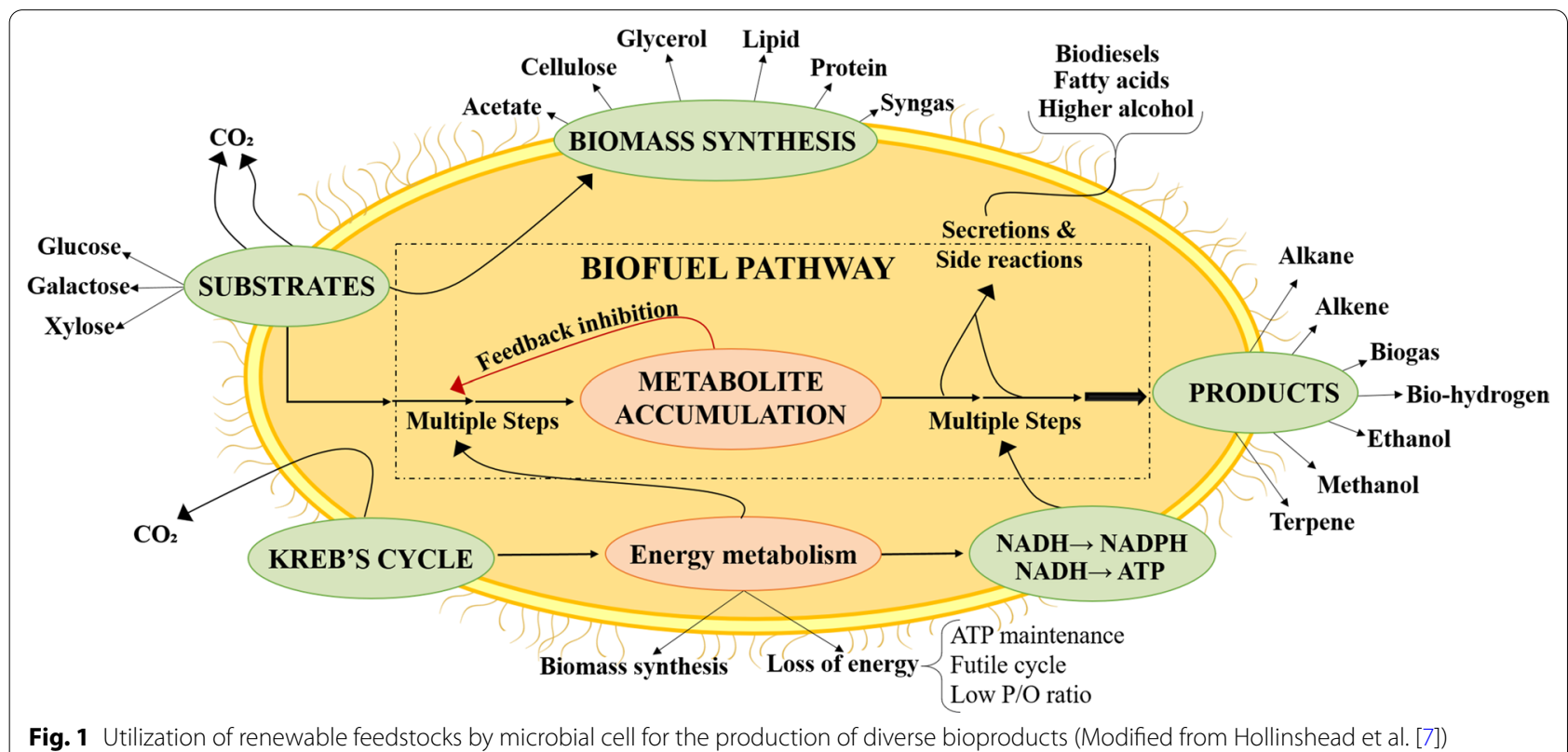

Fig. 1 Utilization of renewable feedstocks by microbial cell for the production of diverse bioproducts (Modified from Hollinshead et al. [7]) 
the biofuel industry; among these, lignocellulose is highly plentiful carbohydrate moiety in the environment, which is ultimately an economical renewable energy asset [15]. (v) Aspergillus spp. secretes exo and endo-inulinases enzymes that have been reported to enhance the formation of fructose from inulin and therefore are recognized as promising assets to enhance the biosynthesis of carbohydrates viz., fructose [16].

\section{Microbial functions in the production of biofuel}

Microbial biofuel production is a field where synthetic feedback regulation has the ability for huge influence as biofuels are beneficial alternative energy which may supplement the present-day occurring fuel resources for instance jet fuel, gasoline, or diesel without demanding engine adjustments or extra infrastructure advancement [17]. Inexpensive and efficient strategies are significantly required in the biofuels industry because the major cost is in the manufacture rather than the beginning material phase in this context, consolidated biological processing (CBP) method is considered as the utmost promising method for creating biofuel generation inexpensive in comparison to those biofuels that are presently used commercially [18]. Consolidated biological processing is an effective method which involves one step change of plant materials to biofuels using microbial agents without requiring saccharolytic enzyme supplementation [18]. Nearly 58 bacterial strains, 17 yeasts species and 24 molds have been reported to have the capacity to make bio-ethanol in comparison to other metabolites using several complex metabolic pathways [19]. Clostridium species have been engineered to use feedstocks for instance liquefied cornflour [20], glucose [21], glycerol which is then produced during the formation of biodiesel from fats [22] and even syngas which is combined mixture of $\mathrm{H}_{2}$ and $\mathrm{CO}$ [23] to enhance butanol manufacture. The yeast competence to develop properly on pre-supplemented lignocellulosic biomass could significantly elevate the lipid accretion, which ultimately offers an efficient practice for the manufacture of economically and ecologically sound microbial oil from agronomic residues [24]. Yet till date, S. cerevisiae is the most used microorganism for the formation of bio-ethanol because of its greater ethanol productivity, tolerance and competence of fermenting several sugars, in comparison to other microbes [25].

Biodiesel production through the use of microbial population such as microalgae, fungi and bacteria are recognized beneficial substitutes for the formation of biodiesel, oil of these oleaginous microorganisms has the potential to be used as the crude moieties for the production of bio-diesel during transesterification [26]. The usage of these quickly developing microorganisms could prove considerably promising as it services a greater form of feedstock such as sugarcane with amazingly bigger product/hectare compared to rape seeds and biological mass, and hence ability to make biodiesel by using a lesser part of arable land [27]. Due to the fast-growing nature, ability to double their biomass within $24 \mathrm{~h}$ and extensively rich in oil, microalgae are considered as one of the chief source of biodiesel that has the capacity to partially substitute fossil diesel requirement [28]. Saccharomyces cerevisiae CHY1011 improved production of bioethanol via employing alkali-treated Miscanthus sacchariflorus as carbon source [29]. Oils can also be produced from rapidly growing microorganisms followed by transesterification via simple chain alcohols, therefore forming an economical superior biodiesel ester that succeeds with current standards [30]. A2A an E. coli strain which uses glucose or hemicellulose to form fatty acids can be employed for biodiesel production [31]. Microbes like blue green algae, a few dark fermenting microbes, and purple non-sulfur photosynthetic bacteria have also been employed in the production of biohydrogen [32] (Fig. 2). $\mathrm{CH}_{4}$ from a landfill or natural gas wells which have otherwise poor performance can be employed straightforwardly by methanotrophs to make fuels, or can be changed to methanol $\left(\mathrm{CH}_{3} \mathrm{OH}\right)$ and ultimately used by methylotroph organisms for fuel generation [4], these microbes oxidize $\mathrm{CH}_{4}$ by firstly starting reduction of oxygen molecules to hydrogen peroxide and after that conversion of $\mathrm{CH}_{4}$ to $\mathrm{CH}_{3} \mathrm{OH}$ using $\mathrm{CH}_{4}$ monooxygenases [33].

\section{Metabolic engineering for biofuel production}

Advancement in the field of the metabolic engineering has accelerated the production of biofuels like fatty acid, alcohols, and gaseous derivatives may have the growing possibility to compete with the fossil fuels being used these days. The following sub-sections, will have discussions on the procedure which is taken into consideration for metabolic engineering. Compilation of the studies showing the metabolic engineering strategies implied to improve the yield of biofuels has been cited in Table 1.

\section{Host selection and deflecting carbon sources}

The selection of an organism is the most important factor for metabolic engineering. Model organisms have always been the target for engineering, however, utilizing the models for exploiting non-model organism is now possible due to the recently developed biological tools like genetic engineering, hybridization, etc. These technology has helped in identifying the organisms that are naturally the overproducers of the biofuels, and when these organisms are engineered, they tend to give likely more yield and productivity. 


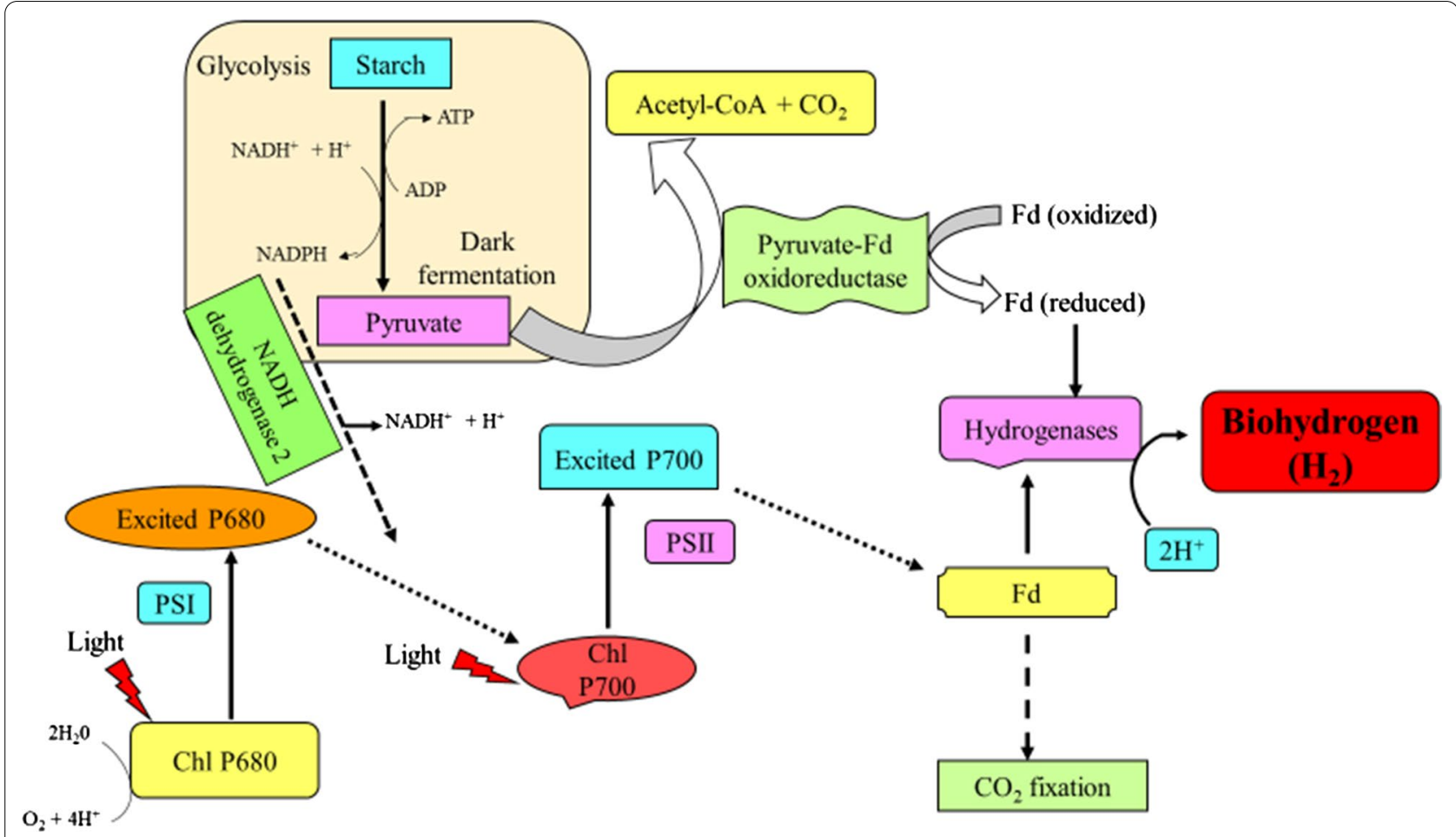

Fig. 2 Microbial production of biofuel biohydrogen (modified from Majidian et al. [28]). Chl-chlorophyll; PSI-Photosystem I; PSII-Photosystem II; Fd-ferridoxin; ATP-adenosine triphosphate; ADP-adenosine diphosphate; NADH- reduced form of nicotinamide adenine dinucleotide; $\mathrm{NADH}^{+}$- oxidized nicotinamide adenine dinucleotide

Like oleaginous organisms that are rich in oily substances when engineered lead to higher production of fatty acid-based products like triacylglycerols (TAGs), fatty acid ethyl esters (FAEEs), fatty acid methyl esters (FAMEs), etc. It was observed when the wild type of Rhodococcus opacus was engineered using the synthetic metabolic pathways, the recombinant strains generated higher amount of free fatty acids (FFAs), FAEEs as well as long-chain hydrocarbons in comparison to the wild type that produced the only triacylglycerol from glucose [41]. Similar to this, another study by Qiao et al. (2017) also highlighted that enhancing the NADPH pool lead to higher production of FAMEs [52]. The organisms not only are used to produce the fatty acidbased product but also the alcohol-based products like ethanol, butanol. Using genetic engineering approach, the $S$. cerevisiae enhanced the production of ethanol, butanol [53]. Moreover, it is also reported that recombinant Clostridium sp. subjected to hot channel process, enhanced the butanol production [37].

Not only engineering the host, but deflecting carbon source also enhances the production of these biofuels like enriching the medium for S. cerevisiae with malonylCoA, NADPH, Acetyl-CoA and ATP which enhances the production of ethanol as well as FFAs [44].

\section{Modulating the supply of reducing power}

Another approach for enhancing the production includes the modulation in the supply of reducing power like $\mathrm{NADPH}, \mathrm{NADH}$, etc. as biofuel production demands a larger amount of reducing power supply [44]. It was observed that engineering the pentose phosphate pathway enriches the NADPH pool that helps in enhancing the production of biofuels as well [54]. Utilizing the given idea Jaroensuk et al. introduced heterologous formate dehydrogenase in the aldehyde-deformylating oxygenase (ADO)-dependent pathway to enrich the NADPH pool that aided in enhanced production of hydrocarbon [43]. However, the introduction of heterologous formate dehydrogenase will lead to the formation of formic acid as a byproduct. Thus, to minimize the formation of byproduct that has no contribution in further production of biofuel, researchers tried to introduce heterologous formate dehydrogenase that can aid to production of aforementioned byproduct that could generate more and more reducing power. Construction of 2,3-butanediol biosynthesis pathway in Clostridium acetobutylicum as $\mathrm{NADH}$-compensating module is also reported and this modulation upgraded the butanol formation [55]. Alternate to this, the interconversion between two reducing power can help in enriching the pool of other reducing 


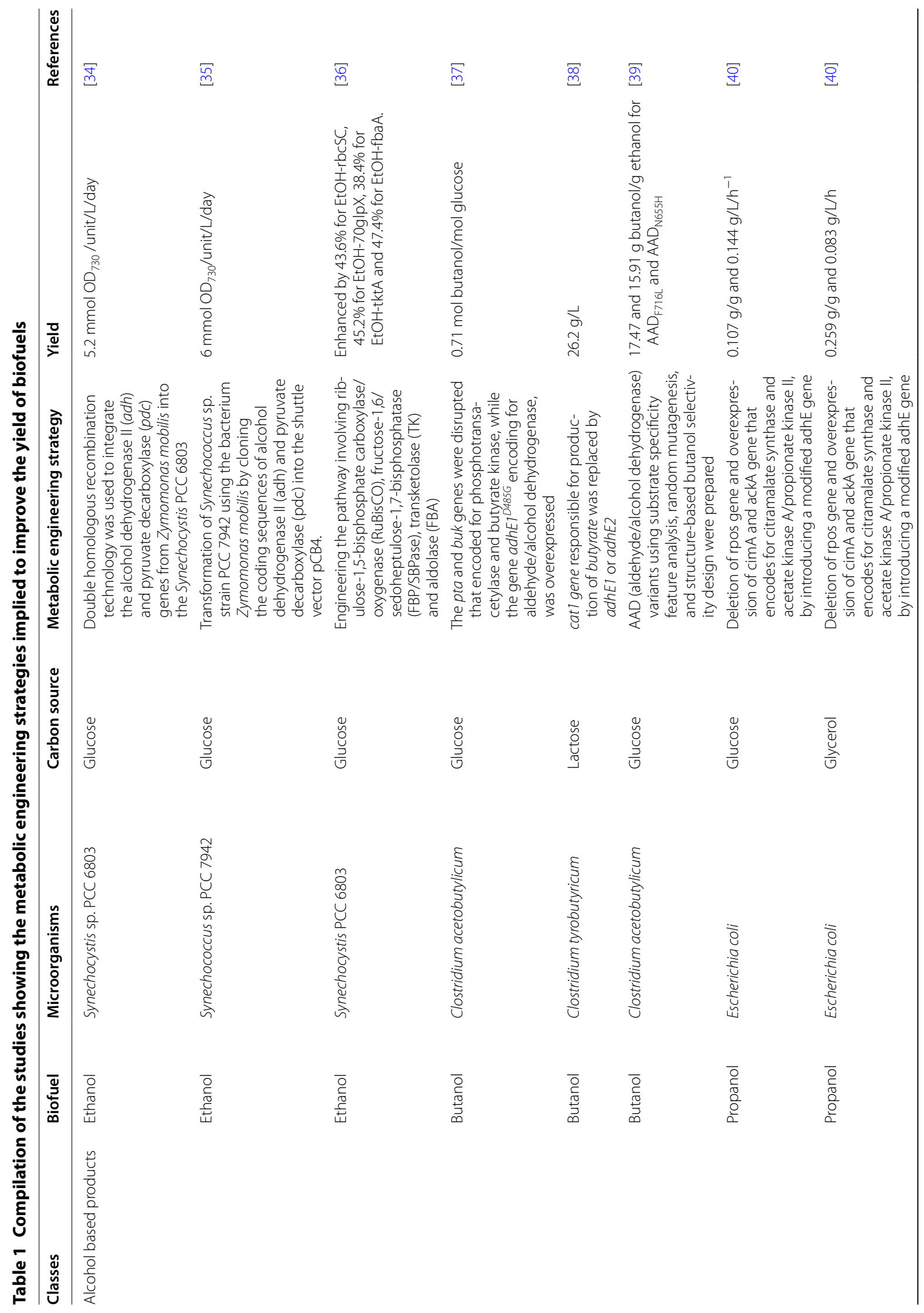




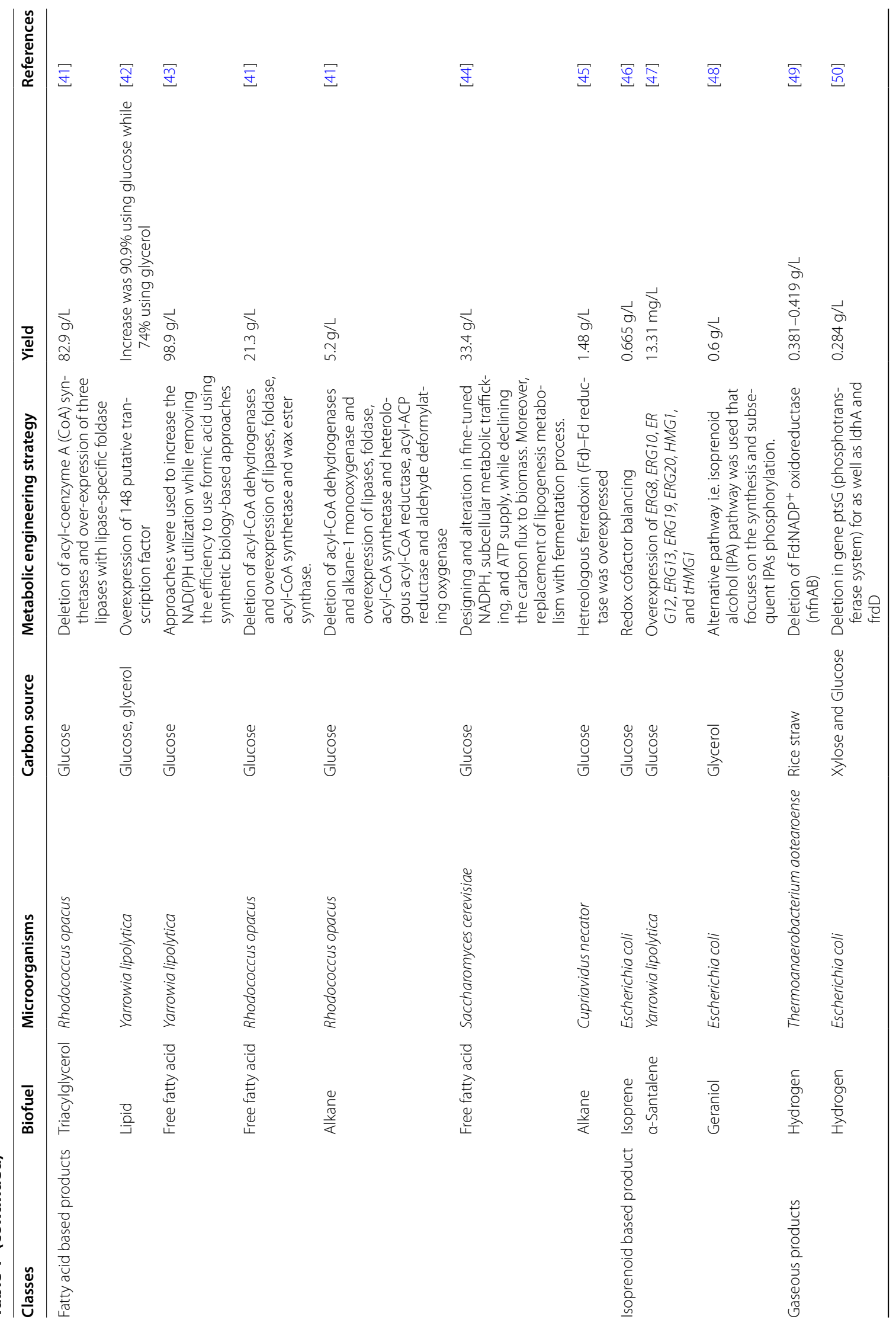




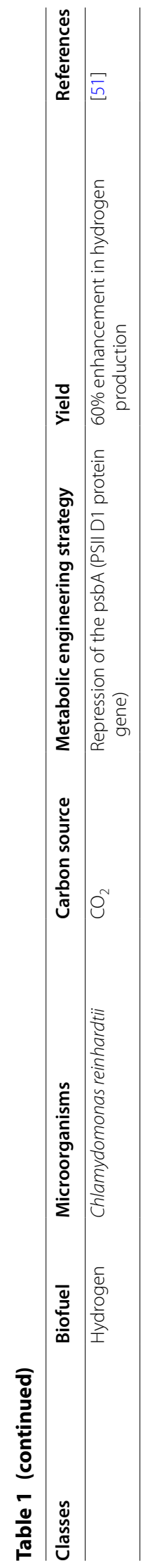


power, likewise coexpression of ferredoxin $(\mathrm{Fd})$ and $\mathrm{Fd}$ reductase genes and knocking down of $n f n A B$ genes that encodes for $\mathrm{NADH}$-dependent $\mathrm{Fd}$ : $\mathrm{NADP}^{+}$oxidoreductase that reduces $\mathrm{NADP}^{+}$by $\mathrm{NADH}$ and $\mathrm{Fd}$, that enriches the Fd pool for production of $\mathrm{H}_{2}$ [45]. Similarly, Wiegand et al. in 2018, engineered the Fd and Fd-NADP ${ }^{+}$-oxidoreductase enzyme so that the transfer of electron declines from Fd and thus securing the pool of Fd for higher production of hydrogen [56].

\section{Biosynthetic enzyme engineering}

Some enzymes are required for enhanced production of biofuels and engineering those enzymes in terms of stability, and catalytic activity helps in achieving the targets of higher titer and productivity. Example for such strategies can be understood by the research of Kudo et al. (2019), wherein they had shown that when non-conserved ADO was engineered conversion efficiency of this enzyme was increased for hydrocarbon production. This strategy can be utilized for the enhanced synthesis of biofuels using type I polyketide synthases that has low solubility and high catalytic functioning, through polyketide biosynthetic pathway [57]. Clostridium acetobutylicum was also engineered to increase the butanol-to-ethanol ratio. In this study the adhE1 (aldehyde/alcohol dehydrogenase) gene was engineered in C. acetobutylicum as such that instead of utilizing acetyl-CoA during acetonebutanol-ethanol fermentation preference would be given to butyryl-CoA and this strategy enhanced the ratio by 5.8-fold (17.47 g butanol/g ethanol). Such a strategy can be combined with the machine learning tools to expedite the engineering of enzymes for superior activity [39].

\section{Engineering new pathways}

Devising new synthetic metabolism helps to facilitate the production of biofuels like isoprene-based products. Bruder et al. (2019) reported the replacement of fatty acid photo decarboxylase with ADO-dependent pathway for conversion of fatty aldehydes to hydrocarbons is more efficient [58]. Moreover, the production of isoprenoids is done using the microbial fermentation but scientists engineered the MEP (2-C-methyl-D-erythritol 4-phosphate) [47] and MVA (mevalonate) pathways for higher production of isopentenyl pyrophosphate (IPP), and dimethylallyl pyrophosphate (DMAPP) [46] that are precursors of isoprenoids and this engineering helped in enhancing the production of farnesene and isoprene. However, in a recent work, the higher flux of same compounds was done using the exogenous supply of isoprenol [59] or prenol compounds [60] and the reason for the addition of these exogenous compound help in enhancing the production of dimethylallyl pyrophosphate (DMAPP) and isopentenyl pyrophosphate (IPP) [48].
These advancements can also be exploited for higher $\mathrm{H}_{2}$ production, the major limitation in $\mathrm{H}_{2}$ production is the labile nature of the pathway towards molecular oxygen produced during the process of photosynthesis. However, this limitation can be overcome by indirect photolysis, dark and light fermentation. But, there is need for developing some $\mathrm{O}_{2}$-tolerant hydrogenases or cytosolic hydrogenases that have an efficient catalytic activity to accelerate biological production of $\mathrm{H}_{2}$ [50].

\section{Alternative low-value carbon source}

The newer researches are trying to utilize carbon sources that are cheaper and non-edible and thus trying to find out newer avenues for producing biofuel. Several researchers have utilized some heterologous machinery to facilitate the use of lignocellulosic derivatives like arabinose, cellulose, lignin [61-64]. To utilize the lignocellulosic derivatives, several engineering in protein folding, modification in post-translational system, systematic optimization of medium, genome-scale modeling have been done [41]. Moreover, improvement in the tolerance of host strains towards the toxic components of lignocellulosic derivatives is also another approach that can be taken into consideration. The shuffling of genomes of such microorganisms that can directly convert lignocellulosic derivatives could also aid in enhanced production of biofuel. Apart from engineering the microorganisms, another approach that can be taken into consideration is separation and conversion of lignin to some aromatic compounds. Not only, lignin but glycerol has also gain attention in recent years because it is produced as a byproduct during the transesterification process used for conversion of lipids to biodiesel [65]. There are several microorganisms like E. coli, Klebsiella spp., Citrobacter spp., Trichosporon spp., Clostridium spp., etc. that can directly utilize glycerol, while strains that cannot utilize the glycerol, heterologous machinery of the phosphorylative pathway (via glycerol-3-phosphate), glycerol transport system and oxidative pathway (via dihydroxyacetone) have been presented [66]. In addition to isoprenes and glycerol, volatile fatty acids (VFAs) that can be obtained from non-sterile, anaerobic fermentation of organic wastes like sewage sludge, animal manure etc., can also be utilized to produce biofuels. Still, there is a lack of knowledge in this context and remains an area of continuous research.

\section{Conclusion and future perspectives}

At present, the most challenging issue is the sustainable utilization of energy and to preserve the valuable assets we need to explore some newer avenues for the production of energy in terms of biofuels, bio-products, etc. These days we have our technology at its verge to find 
some alternative system, and in this context, we came across some engineering technologies that have paved new pathways for utilizing diverse microorganisms to enhance the production of biofuels. In this article, the role of microorganisms in biofuel production, the strategies/ideas and the processes used for engineering these microorganisms have been discussed. Advancement in a couple of years in the field of the metabolic engineering has accelerated the production of biofuels like fatty acid, alcohols, gaseous derivatives, that has potential to compete with the fossil fuels being used these days. In this review article, we have discussed the recent challenge of energy demands and the technologies/strategies that are being employed to meet those demands.

Although there is a huge advancement in the strategies, as well as tools to understand the production mechanism for biofuels or other products but the paradigm has shifted towards the cost-effective approach and researchers, are still needed in this direction. Synthesis of biofuels require a huge amount of reducing powers for reduction of carbon residues but still in this process, a large amount of $\mathrm{CO}_{2}$ is lost and not utilized in ethanol production. We need to minimize the cost that is spent on maintaining the fermentation process because not all the plant biomass is utilized in biofuel production, some biomass goes in vain. Another thing that should be focussed is by utilizing low-value carbon sources that can lessen the burden on edible carbon sources. Such strategies that are being deployed should be worked upon, and this may expedite the replacement of biofuels with the conventional energy sources.

\section{Acknowledgements}

Simranjeet Singh is thankful to the ICWaR Indian Institute of Sciences Bangalore for the financial assistance in the form of IOE-IISC Fellowship (Sr. No: IE/ REAC-20-0134) and for providing laboratory and library facilities.

\section{Authors' contributions \\ PCR and SS have contributed in exploring literature and writing. JS, RP, AK and SS conceptualized, and acquired the entire concept and guided the authors for writing this review. PCR, SS, DK, PP, and RP have made the contributions, including drafting and data verification. All authors read and approved the final manuscript.}

\section{Ethics approval and consent to participate}

This article does not contain any studies with animals performed by any of the authors.

\section{Competing interests}

The authors declare that they have no conflict of interest.

\footnotetext{
Author details

${ }^{1}$ Interdisciplinary Centre for Water Research (ICWaR), Indian Institute of Sciences, Bangalore, India. ${ }^{2}$ Department of Botany, Lovely Professional University, Phagwara, Punjab, India. ${ }^{3}$ Department of Botany, Mahatma Gandhi Central University, Motihari, Bihar, India. ${ }^{4}$ School of Plant Sciences, College of Agriculture and Environmental Sciences, Haramaya University, Box-138, Dire Dawa, Ethiopia. ${ }^{5}$ Department of Microbiology, Lovely Professional University,
}

Phagwara, Punjab, India. ${ }^{6}$ Waste Valorization Research Lab, Lovely Professional University, Phagwara, Punjab, India.

Received: 23 December 2020 Accepted: 18 February 2021

Published online: 02 March 2021

\section{References}

1. Natarajan A, Bhatt AS. Microbes and microbiomes in 2020 and beyond. Nat Commun. 2020;11. https://www.nature.com/articles/s41467-02018850-6. Accessed 16 Dec 2020.

2. Kumar R, Kumar P. Future microbial applications for bioenergy production: a perspective. Front Microbiol. 2017;8:450. https://doi.org/10.3389/ fmicb.2017.00450/full.

3. Souza Guimaraes LH. Carbohydrates from Biomass: Sources and Transformation by Microbial Enzymes. Carbohydrates - Compr Stud Glycobiol Glycotechnol. InTech; 2012. http://www.intechopen.com/books/carbo hydrates-comprehensive-studies-on-glycobiology-and-glycotechnology /carbohydrates-from-biomass-sources-and-transformation-by-microbialenzymes. Accessed 16 Dec 2020.

4. Liao JC, Mi L, Pontrelli S, Luo S. Thermohaline circulation Fuelling the future: microbial engineering for the production of sustainable biofuels. Nat Publ Gr. 2016; www.nature.com/nrmicro. Accessed 16 Dec 2020.

5. Dow M, Molinaro A, Cooper RM, Newman MA. Microbial glycosylated components in plant disease. Microb Glycobiol. 2010, p. 803-20.

6. von Itzstein M, Moran AP. Future potential of glycomics in microbiology and infectious diseases. Microb Glycobiol. Elsevier Inc.; 2010. p. 981-6.

7. Hollinshead W, He L, Tang YJ (2014) Biofuel production: an odyssey from metabolic engineering to fermentation scale-up. Front Microbiol 5:344.

8. Kilbane JJ. Future applications of biotechnology to the energy industry. Front Microbiol. 2016;7:86. https://doi.org/10.3389/fmicb.2016.00086/ abstract.

9. Kapdan IK, Kargi F. Bio-hydrogen production from waste materials. Enzyme Microb Technol. 2006;38:569-82.

10. Huang J, Chen D, Wei Y, Wang Q, Li Z, Chen Y, et al. Direct ethanol production from lignocellulosic sugars and sugarcane bagasse by a recombinant trichoderma reesei strain hj48. Sci World J. 2014;2014.

11. Fatma S, Saleem A, Tabassum R. Wheat straw hydrolysis by using cocultures of Trichoderma reesei and Monascus purpureus toward enhanced biodegradation of the lignocellulosic biomass in bioethanol biorefinery. Biomass Convers Biorefin. 2020:1-2.

12. Rastogi $M$, Shrivastava $S$. Recent advances in second generation bioethanol production: an insight to pretreatment, saccharification and fermentation processes. Renew Sustain Energy Rev. 2017;80:330-40.

13. Eliana C, Ritter T, Camassola M, Zampieri D, Silveira MM, José A, et al. Cellulase and Xylanase Production by Penicillium echinulatum in Submerged Media Containing Cellulose Amended with Sorbitol. Artic ID [Internet]. Hindawi Publishing Corporation Enzyme Research; 2013 [cited 2020 Dec 16];2013.

14. Ellis JT, Magnuson TS. Thermostable and alkalistable xylanases produced by the Thermophilic Bacterium Anoxybacillus flavithermus TWXYL3. ISRN Microbiol. 2012;2012:1-8.

15. Yeoman CJ, Han Y, Dodd D, Schroeder CM, Mackie RI, Cann IKO. Thermostable enzymes as biocatalysts in the biofuel industry. Adv Appl Microbiol. 2010;70:1-55.

16. Ricca E, Calabrò V, Curcio S, Iorio G. The state of the art in the production of fructose from inulin enzymatic hydrolysis. Crit Rev Biotechnol. 2007. https://doi.org/10.1080/07388550701503477.

17. Dunlop MJ, Keasling JD, Mukhopadhyay A. A model for improving microbial biofuel production using a synthetic feedback loop. Syst Synth Biol. 2010. https://doi.org/10.1007/s11693-010-9052-5.

18. Elshahed MS. Microbiological aspects of biofuel production: current status and future directions. J Adv Res. 2010;1:103-11.

19. Chen X, Gu Y, Zhou X, Zhang Y. Asparagus stem as a new lignocellulosic biomass feedstock for anaerobic digestion: increasing hydrolysis rate, methane production and biodegradability by alkaline pretreatment. Bioresour Technol. 2014:164:78-85.

20. Ezeji TC, Qureshi N, Blaschek HP. Production of acetone butanol (AB) from liquefied corn starch, a commercial substrate, using Clostridium beijerinckil 
coupled with product recovery by gas stripping. J Ind Microbiol Biotechnol. 2007. https://doi.org/10.1007/s10295-007-0253-1.

21. Qureshi N, Blaschek HP. Production of acetone butanol ethanol (ABE) by a hyper-producing mutant strain of Clostridium beijerinckii BA101 and recovery by pervaporation. Biotechnol Prog. 1999;15:594-602. https://doi. org/10.1021/bp990080e.

22. Malaviya A, Jang YS, Lee SY. Continuous butanol production with reduced byproducts formation from glycerol by a hyper producing mutant of Clostridium pasteurianum. Appl Microbiol Biotechnol. 2012;93:1485-94. https://pubs.acs.org/sharingguidelines. Accessed 16 Dec 2020.

23. Köpke M, Held C, Hujer S, Liesegang H, Wiezer A, Wollherr A, et al. Clostridium ljungdahlii represents a microbial production platform based on syngas. Proc Natl Acad Sci U S A. 2010;107:13087-92. Available from: www.pnas.org/cgi/doi/10.1073/pnas.1011320107www.pnas. org/cgi/doi/10.1073/pnas.1010816107www.pnas.org/cgi/doi/10.1073/ pnas.1011244107www.pnas.org/cgi/doi/10.1073/pnas.1010446107www. pnas.org. Accessed 16 Dec 2020

24. Nigam PS, Singh A. Production of liquid biofuels from renewable resources. Prog Energy Combust Sci Pergamon. 2011;37:52-68.

25. Selim K, El-Ghwas D, Easa S, Abdelwahab Hassan M. Bioethanol a microbial biofuel metabolite; new insights of yeasts metabolic engineering. Fermentation. MDPI AG; 2018;4:16. http://www.mdpi.com/23115637/4/1/16. Accessed 16 Dec 2020.

26. Meng X, Yang J, Xu X, Zhang L, Nie Q, Xian M. Biodiesel production from oleaginous microorganisms. Renew Energy. 2009;34:1-5.

27. Al Makishah NH. Bioenergy: Microbial Biofuel Production Advancement. Available onlinewww.ijpras.com Int J Pharm Res Sci. 2017;6:93-106. www. ijpras.com. Accessed 16 Dec 2020.

28. Majidian P, Tabatabaei M, Zeinolabedini M, Naghshbandi MP, Chisti Y. Metabolic engineering of microorganisms for biofuel production. Renew Sustain Energy Rev. 2018;82:3863-85.

29. Kang KE, Chung DP, Kim Y, Chung BW, Choi GW. High-titer ethanol production from simultaneous saccharification and fermentation using a continuous feeding system. Fuel. 2015;145:18-24.

30. Vicente G, Bautista LF, Gutiérrez FJ, Rodríguez R, Martínez V, RodríguezFrómeta RA, et al. Direct transformation of fungal biomass from submerged cultures into biodiesel. Energy and Fuels [Internet]. American Chemical Society; 2010;24:3173-8. https://pubs.acs.org/sharingguidelin es. Accessed 16 Dec 2020

31. Koppolu V, Vasigala VK. Role of Escherichia coli in biofuel production. Microbiol Insights. 2016;9:MBI.S10878. https://doi.org/10.4137/MBI.S1087 8.

32. Rollin JA, Del Campo JM, Myung S, Sun F, You C, Bakovic A, et al. Highyield hydrogen production from biomass by in vitro metabolic engineering: mixed sugars coutilization and kinetic modeling. Proc Natl Acad Sci USA. 2015. https://doi.org/10.1073/pnas.1417719112.

33. Fuerst JA. Planctomycetes: Cell structure, origins and biology. Planctomycetes Cell Struct. Orig. Biol. Humana Press Inc.; 2014.

34. Dexter J, Fu P. Metabolic engineering of cyanobacteria for ethanol production. Energy Environ Sci Royal Society of Chemistry; 2009;2:857-64. https://pubs.rsc.org/en/content/articlehtml/2009/ee/b811937f. Accessed 16 Dec 2020

35. Deng M De, Coleman JR. Ethanol synthesis by genetic engineering in cyanobacteria. Appl Environ Microbiol [Internet]. American Society for Microbiology; 1999 [cited 2020 Dec 16];65:523-8. Available from: http:// aem.asm.org/.

36. Liang F, Englund E, Lindberg P, Lindblad P. Engineered cyanobacteria with enhanced growth show increased ethanol production and higher biofuel to biomass ratio. Metab Eng. 2018;46:51-9.

37. Lee SY, Jang YS, Lee JY, Lee J, Park JH, Im JA, et al. Enhanced butanol production obtained by reinforcing the direct butanol-forming route in Clostridium acetobutylicum. MBio. American Society for Microbiology; 2012;3. http://mbio.asm.org/. Accessed 16 Dec 2020.

38. Zhang J, Zong W, Hong W, Zhang ZT, Wang Y. Exploiting endogenous CRISPR-Cas system for multiplex genome editing in Clostridium tyrobutyricum and engineer the strain for high-level butanol production. Metab Eng. 2018;47:49-59.

39. Cho C, Hong S, Moon HG, Jang YS, Kim D, Lee SY. Engineering clostridial aldehyde/alcohol dehydrogenase for selective butanol production. MBio. 2019. https://doi.org/10.1128/mBio.02683-18.
40. Jun Choi Y, Hwan Park J, Yong Kim T, Yup Lee S. Metabolic engineering of Escherichia coli for the production of 1-propanol. Metab Eng. Academic Press. 2012;14:477-86.

41. Kim HM, Chae TU, Choi SY, Kim WJ, Lee SY. Engineering of an oleaginous bacterium for the production of fatty acids and fuels. Nat Chem Biol. 2019;15:721-9. https://www.nature.com/articles/s41589-019-0295-5. Accessed 16 Dec 2020.

42. Leplat C, Nicaud J-M, Rossignol T. Overexpression screen reveals transcription factors involved in lipid accumulation in Yarrowia lipolytica. FEMS Yeast Res. 2018;18:37. https://doi.org/10.1093/femsyr/foy037/49565 24.

43. Jaroensuk J, Intasian P, Kiattisewee C, Munkajohnpon P, Chunthaboon $P$, Buttranon $S$, et al. Addition of formate dehydrogenase increases the production of renewable alkane from an engineered metabolic pathway. $\mathrm{J}$ Biol Chem [Internet]. American Society for Biochemistry and Molecular Biology Inc.; 2019;294:11536-48. http://www.jbc.org/. Accessed 16 Dec 2020.

44. Yu T, Zhou YJ, Huang M, Liu Q, Pereira R, David F, et al. Reprogramming yeast metabolism from alcoholic fermentation to lipogenesis. Cell. 2018:174:1549-58.

45. Crépin L, Barthe M, Leray F, Guillouet SE. Alka(e)ne synthesis in Cupriavidus necator boosted by the expression of endogenous and heterologous ferredoxin-ferredoxin reductase systems. Biotechnol Bioeng. 2018;115:2576-84. https://doi.org/10.1002/bit.26805.

46. Guo J, Cao Y, Liu H, Zhang R, Xian M, Liu H. Improving the production of isoprene and 1,3-propanediol by metabolically engineered Escherichia coli through recycling redox cofactor between the dual pathways. Appl Microbiol Biotechnol. 2019. https://doi.org/10.1007/s00253-018-09578-X.

47. Jia D, Xu S, Sun J, Zhang C, Li D, Lu W. Yarrowia lipolytica construction for heterologous synthesis of a-santalene and fermentation optimization. Appl Microbiol Biotechnol. 2019:103:3511-20. https://doi.org/10.1007/ s00253-019-09735-w.

48. Clomburg JM, Qian S, Tan Z, Cheong S, Gonzalez R. The isoprenoid alcohol pathway, a synthetic route for isoprenoid biosynthesis. Proc Natl Acad Sci USA. 2019;116:12810-5. https://www.pnas.org/content/116/26/12810 Accessed 16 Dec 2020

49. LiY, Hu J, Qu C, Chen L, Guo X, Fu H, et al. Engineered Thermoanaerobacterium aotearoense with nfnAB knockout for improved hydrogen production from lignocellulose hydrolysates. Biotechnol Biofuels. 2019. https://doi.org/10.1186/s13068-019-1559-8.

50. Balderas-Hernandez VE, Landeros Maldonado KP, Sánchez A, Smoliński A, De Leon Rodriguez A. Improvement of hydrogen production by metabolic engineering of Escherichia coli: modification on both the PTS system and central carbon metabolism. Int J Hydrogen Energy. 2020;45:5687-96.

51. Li H, Liu Y, Wang Y, Chen M, Zhuang X, Wang C, et al. Improved photobio$\mathrm{H} 2$ production regulated by artificial miRNA targeting psbA in green microalga Chlamydomonas reinhardtii. Biotechnol Biofuels. 2018. https:// doi.org/10.1186/s13068-018-1030-2.

52. Qiao K, Wasylenko TM, Zhou K, Xu P, Stephanopoulos G. Lipid production in Yarrowia lipolytica is maximized by engineering cytosolic redox metabolism. Nat Publ Gr. 2017;35. https://www.nature.com/nbt/journal/ v35/n2/abs/nbt.3763.html. Accessed 16 Dec 2020.

53. Lee SY, Kim HU, Chae TU, Cho JS, Kim JW, Shin JH, et al. A comprehensive metabolic map for production of bio-based chemicals. Nat Catal. 2019:2:18-33. https://www.nature.com/articles/s41929-018-0212-4. Accessed 16 Dec 2020

54. Kumaraswamy KG, Krishnan A, Ananyev G, Zhang S, Bryant DA, Dismukes GC. Crossing the Thauer limit: Rewiring cyanobacterial metabolism to maximize fermentative $\mathrm{H} 2$ production. Energy Environ Sci. Royal Society of Chemistry; 2019;12:1035-45. https://pubs.rsc.org/en/content/artic lehtml/2019/ee/c8ee03606c. Accessed 16 Dec 2020.

55. Liu D, Yang Z, Chen Y, Zhuang W, Niu H, Wu J, et al. Clostridium acetobutylicum grows vegetatively in a biofilm rich in heteropolysaccharides and cytoplasmic proteins. Biotechnol Biofuels. 2018;11:315. https://doi. org/10.1186/s13068-018-1316-4.

56. Wiegand K, Winkler M, Rumpel S, Kannchen D, Rexroth S, Hase T, et al. Rational redesign of the ferredoxin-NADP + -oxido-reductase/ferredoxininteraction for photosynthesis-dependent $\mathrm{H} 2$-production. Biochim Biophys Acta Bioenerg. 2018;1859:253-62.

57. Kudo H, Hayashi Y, Arai M. Identification of non-conserved residues essential for improving the hydrocarbon-producing activity of cyanobacterial 
aldehyde-deformylating oxygenase. Biotechnol Biofuels. 2019. https:// doi.org/10.1186/s13068-019-1409-8.

58. Bruder S, Moldenhauer EJ, Lemke RD, Ledesma-Amaro R, Kabisch J. Dropin biofuel production using fatty acid photodecarboxylase from Chlorella variabilis in the oleaginous yeast Yarrowia lipolytica. Biotechnol Biofuels. 2019. https://doi.org/10.1186/s13068-019-1542-4.

59. Lund S, Hall R, Williams GJ. An Artificial Pathway for Isoprenoid Biosynthesis Decoupled from Native Hemiterpene Metabolism. ACS Synth Biol. American Chemical Society; 2019; https://pubs.acs.org/sharingguidelin es. Accessed 16 Dec 2020.

60. Chatzivasileiou AO, Ward V, Edgar SMB, Stephanopoulos G. Two-step pathway for isoprenoid synthesis. Proc Natl Acad Sci USA [Internet]. National Academy of Sciences; 2019;116:506-11. https://www.pnas.org/ content/116/2/506. Accessed 16 Dec 2020 .

61. Song X, Li Y, Wu Y, Cai M, Liu Q, Gao K, et al. Metabolic engineering strategies for improvement of ethanol production in cellulolytic Saccharomyces cerevisiae. FEMS Yeast Res. 2018. https://doi.org/10.1093/femsyr/foy09 0/5071949.

62. Bracher JM, Verhoeven MD, Wisselink HW, Crimi B, Nijland JG, Driessen AJM, et al. The Penicillium chrysogenum transporter PcAraT enables high-affinity, glucose-insensitive l-arabinose transport in Saccharomyces cerevisiae. Biotechnol Biofuels. 2018;11:1-16. https://doi.org/10.1186/ s13068-018-1047-6.

63. Merkx-Jacques A, Rasmussen H, Muise DM, Benjamin JJR, Kottwitz $H$, Tanner K, et al. Engineering xylose metabolism in thraustochytrid T18. Biotechnol Biofuels. 2018;11:1-18. https://doi.org/10.1186/s1306 8-018-1246-1.

64. Promdonkoy P, Siripong W, Downes JJ, Tanapongpipat S, Runguphan W. Systematic improvement of isobutanol production from d-xylose in engineered Saccharomyces cerevisiae. AMB Express. 2019:9:1-14. https://. doi.org/10.1186/s13568-019-0885-3.

65. Monteiro S, Santos R. Enzymatic and viability RT-qPCR assays for evaluation of enterovirus, hepatitis A virus and norovirus inactivation: implications for public health risk assessment. J Appl Microbiol. 2018. https://doi. org/10.1111/jam.13568.

66. Semkiv MV, Ruchala J, Dmytruk KV, Sibirny AA. 100 years later, what is new in glycerol vioproduction? Trends Biotechnol. 2020. p. 907-16.

\section{Publisher's Note}

Springer Nature remains neutral with regard to jurisdictional claims in published maps and institutional affiliations.
Ready to submit your research? Choose BMC and benefit from:

- fast, convenient online submission

- thorough peer review by experienced researchers in your field

- rapid publication on acceptance

- support for research data, including large and complex data types

- gold Open Access which fosters wider collaboration and increased citations

- maximum visibility for your research: over $100 \mathrm{M}$ website views per year

At BMC, research is always in progress.

Learn more biomedcentral.com/submissions 